\title{
ESTUDIO COMPARATIVO DEL COMPORTAMIENTO DE SEIS CEPAS DE HONGOS MICORRÍZICOS ARBUSCULARES EN SU INTERACCIÓN CON EL TOMATE (Lycopersicon esculentum M. var "Amalia")
}

\section{COMPARATIVE STUDY OF BEHAVIOUR OF SIX ARBUSCULAR MYCORRHIZAL FUNGI WHEN COLONIZE TOMATO PLANTS (Lycopersicon esculentum M. var "Amalia")}

\author{
Yakelin Rodríguez Yon ${ }^{1}$, Blanca de la Noval Pons ${ }^{2}$, Félix Fernández Martín ${ }^{3}$ y Pedro Rodríguez Hernández ${ }^{4}$
}

\begin{abstract}
Resumen
Dada la extraordinaria importancia ecológica y económica de los hongos micorrízicos arbusculares (HMA), en Cuba y otros países, se han dado pasos acelerados para poner en práctica su uso como biofertilizante. En el presente trabajo se realizó un estudio comparativo del comportamiento de seis cepas de HMA, en su interacción con plántulas de tomate de la variedad "Amalia", mediante indicadores fúngicos, agronómicos y bioquímicos con el objetivo de evaluar las diferencias existentes en los patrones de colonización de las distintas cepas y seleccionar la más promisoria para este cultivo en las condiciones estudiadas. Las cepas de HMA estudiadas fueron Glomus fasciculatum, G. clarum, G. mosseae, Glomus sp.1, G. intrarradices y Acaulospora scrobiculata. A los 18 y 32 días de germinadas las semillas se evaluó: altura; masa fresca y seca (aérea, radical y total) y la actividad específica radical de quitinasa, $\beta$-1,3-glucanasa y fenilalanina amonio liasa (PAL); así como las variables fúngicas colonización (\%) y densidad visual (\%) a los 32 días. En sentido general, se encontró un efecto positivo de la inoculación sobre las plántulas de tomate con respecto a los controles, expresado en los indicadores agronómicos y fúngicos estudiados. Los resultados mostraron además respuestas diferenciadas de las plántulas de tomate en función de las cepas de HMA inoculadas, con relación a las actividades enzimáticas, destacándose la cepa Glomus fasciculatum como la más efectiva para esta interacción en las condiciones estudiadas.
\end{abstract}

Palabras claves: hongos micorrízicos arbusculares, tomate, quitinasa, $\beta$-1,3-glucanasa, PAL

\begin{abstract}
Due to ecological and economical importance of arbuscular mycorrhizal fungi (AMF), in Cuba and others countries, there are programs for their introduction as a biofertilizers. The present work aimed to do a comparative study of six AMF strains, in their interaction with tomato seedlings "Amalia" variety, through fungal, agronomics and biochemical indicators with the aim to evaluate the colonization pattern differences of the different strains and select the best strain for this crop under the studied conditions. The AMF strains studied were Glomus fasciculatum, G. clarum, G. mosseae, Glomus sp.1, G. intrarradices y Acaulospora scrobiculata. At 18 and 32 days after seed germination, height, fresh and dry mass (aerial, radical and total) and radical specific activity of chitinase, $\beta-1,3-$ glucanase and phenylalanine ammonia lyase (PAL); as well as fungal variables of colonization (\%) and visual density (\%) at 32 days. In general, a positive effect of inoculation on tomato seedlings expressed in agronomic and fungal indicators studied was found. Enzymatic activities showed different responses in tomato seedlings according to AMF strains, being $G$. fasciculatum the most effective strain for this interaction under the studied conditions.
\end{abstract}

Key words: arbuscular mycorrhizal fungi, tomato, chitinase, $\beta$-1,3-glucanase, PAL

\section{Introducción}

A pesar que los hongos micorrízicos arbusculares (HMA) surgieron hace 350 - 460 millones de años atrás (Simon et al., 1993), en la actualidad poseen una extraordinaria importancia ecológica y económica producto a los beneficios que reportan a la mayoría de las plantas terrestres, además de sustentar los programas basados en la conservación medioambiental.

Esta asociación no es específica puesto que cualquiera de los HMA puede colonizar a cualquiera de las plantas susceptibles de formar la simbiosis. Sin embargo, algunos hongos benefician en mayor grado a un determinado hospedero en comparación con otros y, fundamentalmente, muestran un cierto grado de adaptación para establecer la micorriza y funcionar bajo determinadas condiciones edafoclimáticas (Pozo, 1999), hecho que evidencia las marcadas diferencias, no solo estructurales, sino también funcionales existentes entre especies e incluso entre cepas pertenecientes a una misma especie. De ahí la importancia de conocer estas diferencias con vistas a seleccionar el hongo adecuado para cada interacción, lo cual permitirá obtener resultados satisfactorios. 
El seguimiento del comportamiento en campo de las plantas colonizadas ha sido muy usado para estos fines, pero estos estudios hoy día se complementan con técnicas más avanzadas como son los marcadores bioquímicos y/o moleculares, que constituyen alternativas más rápidas, sensibles $\mathrm{y}$ confiables (Koslova et al., 2000; Morton \& Redecker, 2001).

Durante el establecimiento de esta simbiosis se producen alteraciones citológicas y metabólicas en las células hospederas, mediadas por señales que se intercambian entre la planta y el hongo (Salzer \& Boller, 2000), detectándose variaciones en la expresión y actividad de algunas enzimas involucradas en los mecanismos de defensa (Dumas-Gaudot et al, 2000). Dentro de estas enzimas se destacan las quitinasas (EC 3.2.1.14) y $\beta$-1,3-glucanasas (EC 3.2.1.39), las cuales hidrolizan los polisacáridos de la pared celular de los hongos, por lo que se ha descrito el papel de las mismas en la resistencia activa de las plantas contra fitopatógenos (Graham \& Sticklen, 1994; Vázquez Garcidueñas et al., 1998), aunque estas enzimas también pueden ser inducidas por elicitores bióticos liberados durante la propia acción del hongo (Boller, 1995).

Por su parte, la fenilalanina amonioliasa (PAL) (EC 4.3.1.5) pertenece a la clase de las liasas y cataliza la desaminación de la L-fenilalanina para producir ácido trans-cinámico y amonio, reacción que constituye el primer paso en la biosíntesis de los fenilpropanoides en plantas superiores (Lister et al., 1996). Mediante esta vía metabólica se sintetizan compuestos como la lignina, suberina, fitoalexinas, flavonoides y compuestos fenólicos en general, cuya síntesis y acumulación es parte de la estrategia desarrollada por las plantas para evitar la infección de patógenos, por lo que la inducción de esta enzima es relevante en los mecanismos de defensa (Espinosa-Victoria, 2000).

Teniendo en cuenta estos aspectos se realizó un estudio comparativo del comportamiento de seis cepas de HMA en su interacción con plántulas de tomate de la variedad "Amalia", mediante indicadores fúngicos, agronómicos y bioquímicos con el objetivo de evaluar las diferencias existentes en los patrones de colonización de las distintas cepas y seleccionar la más promisoria para este cultivo en las condiciones estudiadas.

\section{Materiales y métodos}

Material vegetal. Para el desarrollo del presente trabajo se utilizó como hospedero plántulas de tomate (Lycopersicon esculentum Mill) de la variedad "Amalia", la cual fue obtenida por el Departamento de Mejoramiento Genético del Instituto Nacional de Ciencias Agrícolas (INCA) de Cuba (Álvarez et al., 1997). Las semillas fueron desinfectadas utilizando una solución de hipoclorito de sodio al $10 \%$ por $10 \mathrm{~min}$. La siembra se efectuó en recipiente metálico $(300 \mathrm{ml})$, en un sustrato estéril compuesto por suelo Ferralítico Rojo (Hernández et al., 1999) y cachaza en la proporción 3:1 (v:v). Las plántulas de tomate crecieron en casa de malla bajo condiciones ambientales de temperatura $\mathrm{y}$ humedad relativa, siendo éstas $22^{0} \mathrm{C}+/-3^{0} \mathrm{C}$ y entre $80-85 \%$, respectivamente, así como iluminación natural. Se utilizó un diseño completamente aleatorizado con 10 réplicas.

Material fúngico. Se estudiaron seis cepas de hongos micorrízicos arbusculares (HMA), pertenecientes a dos géneros, los cuales representan los tratamientos estudiados conjuntamente con el control (Tabla 1).

Tabla 1. Tratamientos estudiados y cepas de hongos micorrízicos arbusculares utilizados.

\begin{tabular}{|c|l|l|}
\hline $\begin{array}{c}\text { Trata- } \\
\text { miento }\end{array}$ & \multicolumn{1}{|c|}{ Cepas } & Procedencia \\
\hline Gf & $\begin{array}{l}\text { Glomus fasciculatum (Gerdeman \& Trappe } \\
\text { emendado por Walker \& Koske) }\end{array}$ & $\begin{array}{l}\text { LAP-1, } \\
\text { Dijon, } \\
\text { Francia }\end{array}$ \\
\hline Gc & Glomus clarum (Nicolson \& Schenck) & $\begin{array}{l}\text { CIAT c-151, } \\
\text { Colombia }\end{array}$ \\
\hline Gm & $\begin{array}{l}\text { Glomus mosseae (Nicol. \& Gerd. } \\
\text { emendado por Gerdeman \& Trappe) }\end{array}$ & Güira, Cuba \\
\hline Gsp & Glomus sp.1 (amarillo) & Güira, Cuba \\
\hline Gi & Glomus intrarradices (Shenck \& Smith) & $\begin{array}{l}\text { Tope de } \\
\text { Collantes, } \\
\text { Cuba }\end{array}$ \\
\hline Asc & Acaulospora scrobiculata (Trappe) & $\begin{array}{l}\text { Tope de } \\
\text { Collantes, } \\
\text { Cuba }\end{array}$ \\
\hline C & Control sin inocular & \\
\hline
\end{tabular}

La inoculación se realizó añadiendo 200 esporas, desinfectadas previamente, por recipiente en el momento de la siembra. La separación de las esporas se realizó según la modificación de Herrera et al. (1995) del protocolo descrito por Gerdemann \& Nicholson (1963). Las 200 esporas se depositaron en viales que contenían $300 \mu$ de solución Ringer para su conservación hasta el momento de la desinfección. La solución Ringer contenía $7.5 \mathrm{~g}$ de $\mathrm{NaCl}, 0.75 \mathrm{~g}$ de $\mathrm{KCl}, 0.1 \mathrm{~g}$ de $\mathrm{CaCl}_{2}$ y $0.1 \mathrm{~g}$ de $\mathrm{NaHCO}_{3}$ en $1 \mathrm{~L}$ de agua destilada.

Desinfección de las esporas. Las esporas fueron sumergidas en una solución de cloramina T (2\%) por $10 \mathrm{~min}$. Posteriormente se lavaron tres veces con agua destilada estéril y a continuación se les añadió una solución de cloramina $\mathrm{T}(5 \%)$ por $10 \mathrm{~min}$. y se lavaron tres veces con agua destilada estéril, esta última etapa se repitió dos veces.

Muestreo y evaluaciones. La toma de muestras se realizó a los 18 y 32 días después de la germinación. Se evaluaron los indicadores agronómicos y se determinaron las actividades enzimáticas, en la parte aérea y radical. Para evaluar los parámetros fúngicos los sistemas radicales fueron cuidadosamente lavados y pesados.

\section{Evaluaciones fúngicas}

Morfología. Se analizaron algunas características morfológicas de las seis cepas de HMA estudiadas (Tabla 2). 
Tabla 2. Características morfológicas de los hongos micorrízicos arbusculares estudiados.

\begin{tabular}{|c|c|c|c|c|}
\hline Cepa & Color & Forma & $\begin{array}{c}\text { Recorrido } \\
(\mu \mathrm{m})\end{array}$ & $\begin{array}{c}\text { No. Paredes de } \\
\text { la espora }\end{array}$ \\
\hline $\begin{array}{c}\text { Glomus } \\
\text { fasciculatum }\end{array}$ & $\begin{array}{l}\text { hialino a } \\
\text { crema } \\
\text { pálido }\end{array}$ & globosa & $60-110$ & 3 capas \\
\hline $\begin{array}{l}\text { Glomus } \\
\text { clarum }\end{array}$ & $\begin{array}{l}\text { amarillo- } \\
\text { ámbar }\end{array}$ & globosa & $100-260$ & $\begin{array}{c}3 \text { capas, la } 3^{\text {ra }} \\
\text { frecuentemente } \\
\text { separada en } \\
\text { esporas } \\
\text { maduras } \\
\end{array}$ \\
\hline $\begin{array}{l}\text { Glomus } \\
\text { mosseae }\end{array}$ & $\begin{array}{l}\text { naranja } \\
\text { pálido }\end{array}$ & $\begin{array}{l}\text { globosa, } \\
\text { subglobosa }\end{array}$ & $100-260$ & $\begin{array}{l}3 \text { capas, se van } \\
\text { formando } \\
\text { según se } \\
\text { diferencia la } \\
\text { pared de la } \\
\text { espora } \\
\end{array}$ \\
\hline Glomus sp1 & $\begin{array}{l}\text { amarillo } \\
\text { a } \\
\text { amarillo } \\
\text { pálido }\end{array}$ & globosa & $60-110$ & $\begin{array}{l}3 \text { capas, la } 2^{\mathrm{da}} \\
\text { es laminada }\end{array}$ \\
\hline $\begin{array}{c}\text { Glomus } \\
\text { intrarradices }\end{array}$ & $\begin{array}{l}\text { blanco a } \\
\text { crema } \\
\text { pálido }\end{array}$ & $\begin{array}{l}\text { globosa, } \\
\text { subglobosa }\end{array}$ & $40-140$ & \begin{tabular}{|c|}
3 capas, sólo la \\
$1^{\text {ra }}$ está \\
presente en \\
esporas \\
jóvenes \\
\end{tabular} \\
\hline $\begin{array}{l}\text { Acaulospora } \\
\text { scrobiculata }\end{array}$ & hialina & subglobosa & $80-160$ & 3 capas \\
\hline
\end{tabular}

Colonización. Se determinaron los porcentajes de colonización micorrízica $(\% \mathrm{C})$ y densidad visual (\%DV) en el segundo período de evaluación (32 días), para ello se tomaron aproximadamente $200 \mathrm{mg}$ de raicillas por tratamiento que fueron secadas a $70^{\circ} \mathrm{C} \mathrm{y}$ teñidas según la metodología descrita por Phillips \& Hayman (1970). La colonización se realizó por el método de los interceptos desarrollado por Giovanetti \& Mosse (1980) y la densidad visual o intensidad de la colonización según metodología descrita por Trouvelot et al. (1986).

Indicadores agronómicos. En ambos periodos de evaluación (18 y 32 días) se determinó la altura de las plántulas de tomate, la masa fresca aérea, radical y total, así como la masa seca aérea, radical y total; esta última se realizó secando a $70^{\circ} \mathrm{C}$ en estufa hasta peso constante.

\section{Estudio de las actividades enzimáticas}

En el tejido radical de las plántulas de tomate se determinó la actividad específica de quitinasa, $\beta-1,3$ glucanasa y fenilalanina amonio liasa (PAL).

Extracción de enzimas. Para la obtención de los extractos enzimáticos radicales se procedió según la metodología descrita y estandarizada por Solórzano (1997), procesándose tres réplicas en cada caso. Se utilizó una solución amortiguadora de extracción Tris$\mathrm{HCl} 50 \mathrm{mM} \mathrm{pH}$ 7.2, en proporción 1:1 (p/v), la cual contenía sacarosa $10 \%$, polivinilpirrolidona $5 \%$ y $\beta$ mercaptoetanol $0.1 \%$. El sobrenadante obtenido se guardó a $-20^{\circ} \mathrm{C}$.

La concentración de proteínas se determinó por el método de Bradford (Bradford, 1976), en un espectrofotómetro Ultrospec 2001 pro.

Quitinasa. La actividad quitinasa se determinó según el método colorimétrico, discontinuo, descrito por Boller et al. (1983), donde se utilizó como sustrato la quitina coloidal obtenida a partir de quitina (calidad reactivo Fluka), registrándose la absorbancia a 585 nm. Para realizar la curva patrón se utilizó una solución de $\mathrm{n}$-acetil glucosamina $\left(1 \mathrm{mg}\right.$. $\left.\mathrm{ml}^{-1}\right)$, a partir de la cual se prepararon las diluciones, a las que se les realizó el mismo procedimiento. Posteriormente, la actividad se cálculo según la expresión:

\section{Actividad enzimática $=$ D.O.. Cot $\cdot \underline{\text { Vens }} \cdot$ dil.}

Donde $t$ incub. es el tiempo de incubación del ensayo, Vens y Venz son los volúmenes de ensayo y enzima, respectivamente y Cot. la cotangente de la curva patrón.

La actividad enzimática se expresó como $\mu$ moles de producto formado/ $\mathrm{min} / \mathrm{ml} \mathrm{enz} \mathrm{(UAE).}$

$\beta-1,3$ glucanasa. Para la determinación de esta actividad se mezcló $50 \mu \mathrm{l}$ de laminarin $(\beta-1,3$ glucano) ( $\left.2 \mathrm{mg} \mathrm{ml}^{-1}\right)$ y $50 \mu \mathrm{L}$ del extracto enzimático, incubándose durante $30 \mathrm{~min}$. a $37{ }^{\circ} \mathrm{C}$. Posteriormente se cuantificaron los azúcares reductores formados a $660 \mathrm{~nm}$ según el método propuesto por Somogyi (1952). La curva patrón se realizó con el uso de glucosa $\left(1 \mathrm{mg} \mathrm{ml}^{-1}\right)$ como estándar, a partir de la cual se prepararon soluciones con distintas concentraciones.

El cálculo y la expresión de esta actividad fue igual que para la quitinasa.

Fenilalanina amonio liasa (PAL). La actividad PAL fue cuantificada según el método discontinuo propuesto por Paynet et al. (1971), que utiliza como sustrato la fenilalanina. En este caso la velocidad de la reacción se calculó a partir de las lecturas de absorbancia a $275 \mathrm{~nm}$, donde se mide el ácido cinámico formado. Este mismo reactivo fue utilizado para hacer la curva patrón.

El cálculo y la expresión de esta actividad fueron iguales que para la quitinasa.

La actividad específica en todos los casos se determinó de la siguiente forma:

Act. Específica $=$ Act. enzimática/ concentración de proteína

y se expresó como UAE. mg proteina ${ }^{-1}$, siendo esta la presentada en los resultados.

Análisis estadístico. Los datos del porcentaje de colonización micorrízica $(\% \mathrm{C})$ fueron transformados por la función $2 \operatorname{arcsen} \sqrt{ } \mathrm{x}$. Esta variable, al igual que la densidad visual, los indicadores agronómicos de las plántulas evaluados (altura, masa fresca y seca aérea, radical y total,) y las actividades específicas 
determinadas fueron sometidas a un análisis de varianza de clasificación simple (ANOVA), siendo las medias con diferencias significativas comparadas según la prueba de rangos múltiples de Duncan para $\mathrm{P} \leq 0.05$.

Todos los análisis estadísticos se ejecutaron con el software SPSS para Windows (SPSS 7.5).

\section{Resultados y discusión}

Colonización fúngica. En la Tabla 3 se muestran los porcentajes de colonización micorrízica y de densidad visual de los tratamientos evaluados en el presente estudio. Al analizar el porcentaje de colonización micorrízica se observa que el valor más elevado se obtuvo en las raíces inoculadas con $G$. fasciculatum, el que alcanzó un $24 \%$, seguido por los tratamientos con A.. scrobiculata, G. clarum y Glomus sp.1, entre los cuales no hubo diferencias significativas, donde se obtuvo un $18 \%$ en el primer caso y un $15 \%$ en los dos últimos. De las plantas micorrizadas, las colonizadas con $G$. mosseae y $G$. intrarradices exhibieron los valores inferiores con un $13 \%$, aunque las mismas no difirieron de los tratamientos que alcanzaron el $15 \%$ ( $G$. clarum y Glomus sp.1).

Tabla 3: Porcentajes de colonización micorrízica (\%C.) y de densidad visual (\%D.V.) en raíces de tomate control e inoculadas con seis cepas de hongos micorrízicos arbusculares, a los 32 días después de la germinación.

\begin{tabular}{|c|c|c|}
\hline Tratamiento & $\% \mathrm{C}$. & $\% \mathrm{D} . \mathrm{V}$. \\
\hline Control & $0 \mathrm{~d}$ & $0 \mathrm{e}$ \\
\hline G. fasciculatum & $24 \pm 0.012 \mathrm{a}$ & $0.80 \pm 0.009 \mathrm{~b}$ \\
\hline G. clarum & $15 \pm 0.006 \mathrm{bc}$ & $0.41 \pm 0.006 \mathrm{~d}$ \\
\hline G. mosseae & $13 \pm 0.012 \mathrm{c}$ & $0.61 \pm 0.000 \mathrm{c}$ \\
\hline Glomus $\mathrm{sp} 1$ & $15 \pm 0.012 \mathrm{bc}$ & $0.37 \pm 0.014 \mathrm{e}$ \\
\hline G. intrarradices & $13 \pm 0.006 \mathrm{c}$ & $0.64 \pm 0.012 \mathrm{c}$ \\
\hline A. scrobiculata & $18 \pm 0.012 \mathrm{~b}$ & $0.88 \pm 0.065 \mathrm{a}$ \\
\hline Sig. & $*$ & $*$ \\
\hline
\end{tabular}

Los valores de cada indicador seguidos de letras comunes no difieren significativamente según la prueba de Duncan $(\mathrm{P} \leq 0.05)$.

Respecto al porcentaje de densidad visual se observan diferencias significativas entre los tratamientos. En primer lugar se destacan las plantas inoculadas con $A$. scrobiculata con un valor de $0.88 \%$ y a continuación las micorrizadas con $G$. fasciculatum con un $0.80 \%$. Seguidamente se encuentran los tratamientos colonizados por $G$. intrarradices y $G$. mosseae, los cuales alcanzaron un $0.64 \%$ y $0.61 \%$, respectivamente, los que no presentaron diferencias significativas entre sí. Los valores más bajos correspondieron a los tratamientos con G. clarum y Glomus sp.1, entre los que no hubo diferencias desde el punto de vista estadístico y fueron de un $0.41 \% \mathrm{y}$ $0.37 \%$, en cada caso.

En las plantas controles no se observó presencia fúngica en la raíz, como era de esperarse pues no fueron inoculadas con el hongo y el sustrato con el cual se trabajó fue esterilizado previamente por lo que se encontraba libre de posibles propágulos, además, las semillas se desinfectaron superficialmente antes de la siembra.

Las diferencias encontradas entre los tratamientos en estos dos indicadores coinciden con lo reportado por Douds et al. (1998), quienes detectaron que las plantas de alfalfa alcanzan niveles de colonización diferentes en dependencia de la especie fúngica inoculada.

Estudios similares realizados por Noval (2000) y por Rodríguez et al. (2001) en plántulas de tomate inoculadas con las cepas $G$. fasciculatum y G. clarum, arrojaron valores te los porcentajes de colonización micorrízica y densidad visual superiores a los obtenidos aquí, oscilando entre $19-40 \%$ y 0.45 y 1.5 $\%$, respectivamente. Estas discrepancias pudieran atribuirse a las diferencias en el método de inoculación y en el sustrato empleados. Estos autores aplicaron el inóculo a la hora de la siembra en el nido de la semilla y utilizaron la tecnología de recubrimiento de las semillas, respectivamente, favoreciendo en ambos casos la colonización debido a la proximidad entre el hongo y las raicillas una vez germinadas las semillas, a la conservación de la micorrizósfera y a la existencia de hifas infectivas y raíces precolonizadas en el inóculo, además de las esporas (Fernández et al., 1999; Ortiz \& Fernández, 1998).

El comportamiento destacado del tratamiento con $G$. fasciculatum en los indicadores fúngicos evaluados coincide con los resultados obtenidos por Hernández (2001) y por Rodríguez et al. (2001).

\section{Indicadores agronómicos}

En la Figura 1 se muestra el comportamiento de la altura de las plántulas en los dos periodos de evaluación estudiados, donde a los 18 días los tratamientos inoculados presentaron valores muy similares (alrededor de los $8 \mathrm{~cm}$ ) por lo que no se observaron diferencias significativas entre ellos, aunque de forma general superaron al control cuya altura fue significativamente inferior $(6.36 \mathrm{~cm})$.

En cambio, a los 32 días sobresalieron las plántulas colonizadas con $G$. intrarradices, $G$. mosseae, $G$. fasciculatum y $G$. clarum, las cuales difirieron significativamente de los controles y cuya altura osciló entre los 18.5 y $20.2 \mathrm{~cm}$. En este período las plántulas inoculadas con $A$. scrobiculata no difirieron del resto de los tratamientos.

Respecto a las masas fresca y seca sólo se muestran los valores totales que reflejan claramente los comportamientos aéreo y radical, estando 
fundamentalmente determinada la masa total por la aérea pues la radical hace una contribución pequeña.

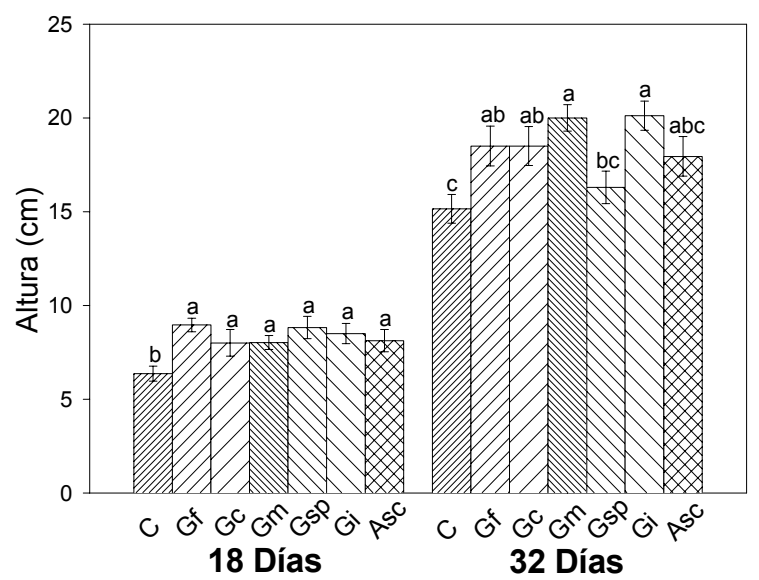

Figura 1. Altura de las plántulas de tomate, var. "Amalia", inoculadas con seis cepas de hongos micorrízicos arbusculares, a los 18 y 32 días de germinadas.

Barras con letras comunes en cada grupo no difieren significativamente según el test de Duncan $(\mathrm{P} \leq 0.05)$.

Leyenda: C- control, Gf- Glomus fasciculatum, Gc- $G$. clarum, Gm- G. mosseae, Gsp- Glomus sp.1, Gi- G. intrarradices, Asc- Acaulospora scrobiculata

En la Figura 2 se observa la masa fresca total, donde a los 18 días sobresalieron por sus valores los tratamientos inoculados con las especies $G$. fasciculatum, G. intrarradices, $G$. mosseae, $A$. scrobiculata y $G$. clarum, entre los que no hubo diferencias significativas. Le siguieron las plántulas colonizadas con Glomus sp.1 y finalmente las controles, con valores de 1.31 y $0.41 \mathrm{~g}$, respectivamente, las cuales difirieron estadísticamente entre ellas y del resto de los tratamientos. A los 32 días se distinguieron dos grupos estadísticamente diferentes, el más destacado abarcó los tratamientos inoculados con G. fasciculatum, G. mosseae, $G$. intrarradices y $G$. clarum, cuyos valores estuvieron entre los 13.75 y $12.22 \mathrm{~g}$, mientras que el segundo agrupó los tratamientos con Glomus sp.1, $A$. scrobiculata y el control, con valores entre $6.69-8.32$ g.

La Figura 3 muestra el comportamiento de la masa seca total en los dos períodos evaluados, donde a los 18 días se destacó el tratamiento inoculado con la especie $G$. intrarradices con un valor igual a $0.38 \mathrm{~g}$, mientras que el resto de los tratamientos no mostraron diferencias significativas entre ellos. Cabe resaltar que los tratamientos inoculados con $G$. mosseae, $G$. clarum, G. fasciculatum y A. scrobiculata, a pesar de tener valores inferiores, no difirieron estadísticamente del tratamiento inoculado con $G$ intrarradices. Sin embargo, a los 32 días los valores más elevados fueron alcanzados por los tratamientos inoculados con las especies $G$. mosseae, $G$. fasciculatum y $G$ intrarradices, entre los que no hubo diferencias significativas y sus respectivos valores fueron 1.54, 1.37 y 1.30 g. Las plántulas colonizadas con $A$. scrobiculata así como las controles mostraron el valor más bajo con $0.68 \mathrm{~g}$, las cuales no presentaron diferencias significativas entre ellas pero si del resto de los tratamientos.

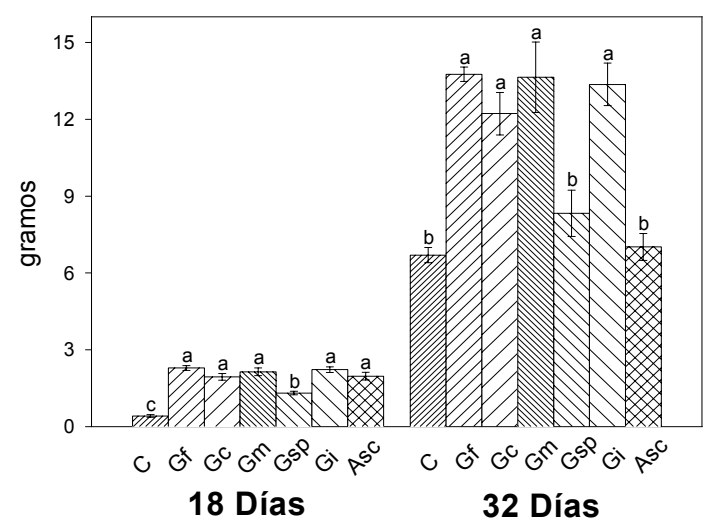

Figura 2. Masa fresca total de las plántulas de tomate, var. "Amalia", inoculadas con seis cepas de hongos micorrízicos arbusculares, a los 18 y 32 días de germinadas.

Barras con letras comunes en cada grupo no difieren significativamente según el test de Duncan $(\mathrm{P} \leq 0.05)$.

Leyenda: C- control, Gf- Glomus fasciculatum, Gc- $G$. clarum, Gm- G. mosseae, Gsp- Glomus sp.1, Gi- G. intrarradices, Asc- Acaulospora scrobiculata.

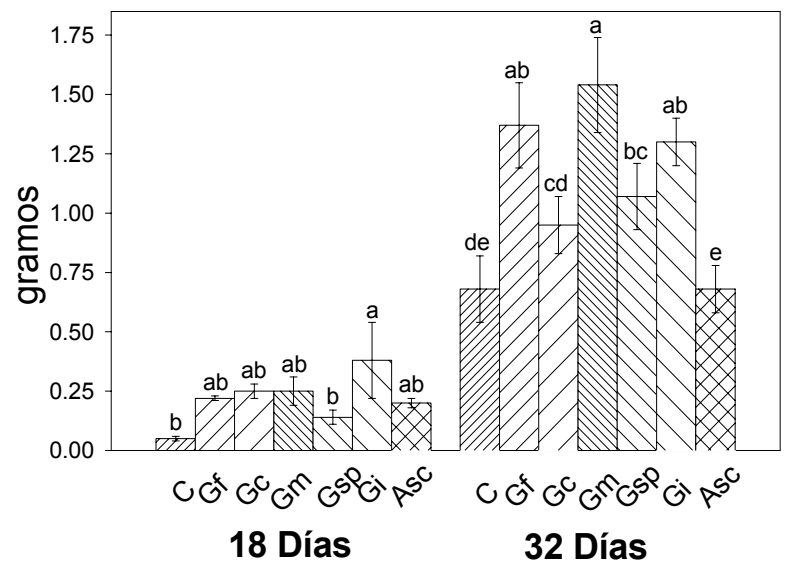

Figura 3: Masa seca total de las plántulas de tomate, var. "Amalia", inoculadas con seis cepas de hongos micorrízicos arbusculares, a los 18 y 32 días de germinadas.

Barras con letras comunes en cada grupo no difieren significativamente según el test de Duncan $(\mathrm{P} \leq 0.05)$. Leyenda: C- control, Gf- Glomus fasciculatum, Gc- $G$. clarum, Gm- G. mosseae, Gsp- Glomus sp.1, Gi- G. intrarradices, Asc-Acaulospora scrobiculata. 

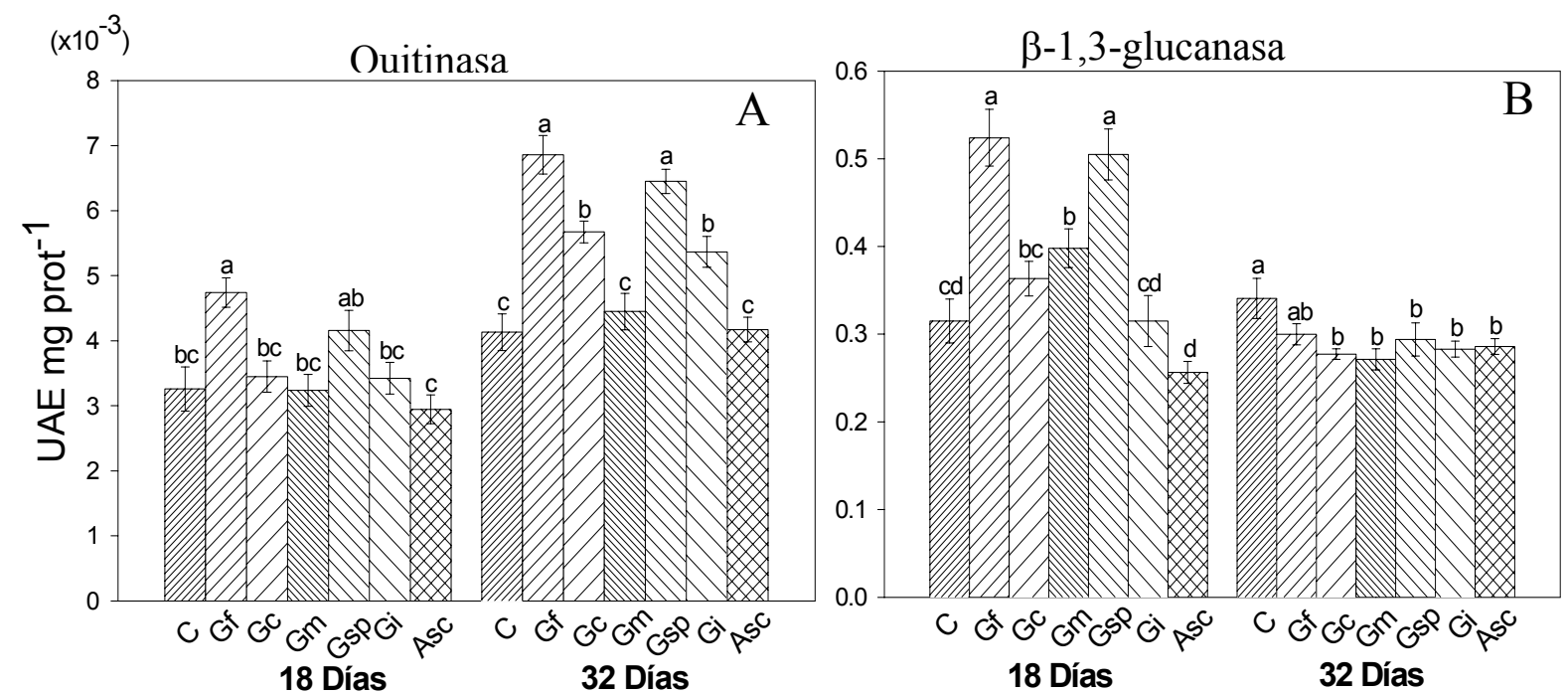

Figura 4: Actividad específica radical de las plántulas de tomate, var. "Amalia", inoculadas con seis cepas de hongos micorrízicos arbusculares, a los 18 y 32 días de germinadas.

Barras con letras comunes en cada grupo no difieren significativamente según el test de Duncan $(\mathrm{P} \leq 0.05)$.

Leyenda: C- control, Gf- Glomus fasciculatum, Gc- G. clarum, Gm- G. mosseae, Gsp- Glomus sp.1, Gi- G. intrarradices, Asc- Acaulospora scrobiculata.

En resumen, los tratamientos que más se destacaron en los indicadores agronómicos de forma general fueron los inoculados con $G$. mosseae, $G$ intrarradices y G. fasciculatum. Las plántulas colonizadas con G. clarum también tuvieron un buen comportamiento en la mayoría de los indicadores evaluados, sin embargo, los valores de masa seca fueron bajos, y debemos considerar la extraordinaria importancia de este indicador en este análisis.

Existen numerosas evidencias del efecto positivo de los HMA en el crecimiento y desarrollo de cultivos de importancia económica, así como en su rendimiento (Fernández et al., 1997; Llonín \& Medina, 2002; Terry et al., 1998). En algunos de estos trabajos se evidencia la necesidad de seleccionar correctamente el tipo de hongo a emplear, según el suelo utilizado, para evitar problemas de "parasitismo" durante el desarrollo de la simbiosis, observándose el comportamiento sobresaliente del tratamiento con $G$. fasciculatum.

Coincidentemente, los resultados de este trabajo corroboran lo anterior, manifestando las plántulas inoculadas con G. fasciculatum un comportamiento destacado, de forma integral, en los indicadores fúngicos y agronómicos analizados a los 32 días.

\section{Actividades enzimáticas en raíz}

Quitinasa y $\beta-1,3$ glucanasa

La Figura 4A muestra los resultados de la actividad específica quitinasa radical en las plántulas de tomate inoculadas con seis cepas de HMA, donde a los 18 días sólo el tratamiento con $G$. fasciculatum superó al control alcanzado $4.74 \times 10^{-3}$ UAE. mg prot $^{-1}$, el resto de los tratamientos micorrizados no presentó diferencias significativas respecto al control. Mientras que a los 32 días, además de este tratamiento, se destacó también el inoculado con Glomus sp.1, al mostrar los valores superiores, seguidos por G. clarum y G. intrarradices, los que difirieron estadísticamente del control.

Respecto a la actividad $\beta-1,3$ glucanasa en raíz (Figura 4B) se observó que a los 18 días los tratamientos con $G$. fasciculatum y Glomus sp.1 alcanzaron los valores más elevados, seguidos por el inoculado $G$. mosseae, los cuales presentaron diferencias significativas entre ellos y respecto al control. El resto de los tratamientos micorrizados no mostró diferencias estadísticas con el control. En cambio, en el segundo período de evaluación se produjo una represión de la actividad en los tratamientos inoculados presentando valores inferiores al control. Sólo el tratamiento con $G$. fasciculatum no mostró diferencias significativas respecto a éste.

Respecto a los cambios observados en la expresión de enzimas de defensa en las plantas micorrizadas, de forma general, se han detectado incrementos localizados en los estadios iniciales, incluso cuando apenas comenzaba a producirse el contacto y la penetración intrarradical, seguidos por una supresión al establecerse completamente la simbiosis (Dumas Gaudot et al., 2000; Noval, 2000; Volpin et al., 1994).

No obstante, se ha encontrado reducción de una quitinasa básica, en raíz, durante la etapa inicial de la 
simbiosis (David et al., 1998), así como la acumulación de ARNm y la expresión de quitinasa ácida clase III, y $\beta$-1,3-glucanasa en estadios tardíos de la micorrización (Dumas-Gaudot et al., 1992; García-Garrido et al., 1992; Salzer \& Boller, 2000).

Como se aprecia existen criterios divergentes en cuanto a la inducción de estas dos enzimas hidrolíticas en esta interacción simbiótica, por lo que no resulta sorprendente las diferencias observadas en el comportamiento de las distintas especies en el presente estudio, donde se destacó de manera integral el tratamiento con G. fasciculatum. Estos resultados corroboran los trabajos realizados por Dumas-Gaudot et al. (1992) y por Pozo (1999), quienes encontraron que existe una respuesta diferente en dependencia de la especie fúngica inoculada, siendo el hongo el responsable de la especificidad.

Para comprender mejor la relación de estas enzimas con la simbiosis MA, debemos considerar que sus sustratos, quitina y $\beta-1,3$ glucanos, están presentes en la pared celular de las distintas estructuras de estos hongos, aunque difieren en cuanto a cantidad y/o forma. Al respecto, Gianinazzi-Pearson et al. (1994) encontraron que en las familias Glomaceae y Acaulosporaceae, la pared de la hifa extrarradical contenía una gran cantidad de $\beta-1,3$ glucanos, pero que eran menos abundantes en la hifa intercelular e indetectables en los arbúsculos (Gollotte et al., 1997). De forma similar, Bonfante-Fasolo (1988) encontró que la organización macromolecular de la quitina en la pared de las diferentes estructuras fúngicas se va modificando a medida que avanza el establecimiento de la simbiosis.

Estos hallazgos sugieren el papel de estas enzimas en el desarrollo de la simbiosis, ya que la acción lítica de ambas favorece la diseminación intrarradical del hongo al irse simplificando la pared, con la formación de las distintas estructuras fúngicas, hasta llegar a los arbúsculos donde es muy fina para facilitar el intercambio de nutrientes y metabolitos entre los simbiontes. También se sugiere que podrían participar en la degradación parcial de la pared vegetal facilitando la penetración (Lambais, 2000).

Por otro lado, las quitinasas inducidas por los HMA pueden hidrolizar los elicitores fúngicos, producidos por la planta ante la llegada de estos hongos, y por tanto atenuar los sistemas de defensa. Salzer \& Boller (2000) plantean que en estadios tardíos, se produce la acumulación de quitinasas específicas inducidas exclusivamente por la micorrización, las cuales inactivan completamente a los oligosacáridos al hidrolizarlos hasta monómeros de $\mathrm{N}$-acetil glucosamina y de esta forma se eliminan las respuestas defensivas rápidas que dan lugar a la síntesis de proteínas PR.

De forma similar, Lambais \& Mehdy (1993) han sugerido el papel de las quitinasas vegetales en la degradación de las estructuras fúngicas colapsadas.
Debemos resaltar que en los arbúsculos la quitina no se mantiene en estado cristalino, siendo sensible a la acción de las quitinasas (Dumas-Gaudot et al., 2000). En apoyo a esta teoría, se han localizado quitinasas y $\beta$-1,3-glucanasas sólo en células que contienen arbúsculos (Blee \& Anderson, 2000; Harrison \& Dixon, 1994) y se ha planteado una posible correlación entre la intensidad de la acumulación de ARNm de glucanasas y quitinasas con la presencia de arbúsculos jóvenes (Blee \& Anderson, 1996).

Todo lo expuesto anteriormente justifica los incrementos en la actividad de ambas enzimas encontrados en el presente estudio. Así a los 18 días la inducción de las quitinasas y $\beta$-1,3-glucanasas podría estar asociada al desarrollo del hongo dentro de la raíz y a su morfogénesis, a la emisión de señales como parte del reconocimiento entre los simbiontes y a la degradación de compuestos que normalmente se acumulan en las interacciones patogénicas, en caso de formarse. Mientras que a los 32 días el aumento en la actividad quitinasa pudiera deberse a la degradación de elicitores fúngicos atenuando las respuestas de defensa y a la formación y degradación de arbúsculos, que constituyen procesos activos en esta fase donde la simbiosis se estableció y es funcional.

De forma general, el tratamiento con $G$. fasciculatum exhibió el mejor comportamiento en ambas actividades con valores superiores al resto de los tratamientos, lo cual sugiere que la interacción de esta especie con las plántulas de tomate está más favorecida para las condiciones estudiadas. Estos resultados confirman los obtenidos por Hernández (2001) y por Solórzano et al. (2001), en estudios similares, así como por Llonín \& Medina (2002) en etapa de campo.

\section{Fenilalanina amonio liasa}

En la Figura 5 se muestran los resultados de la actividad fenilalanina amonio liasa (PAL) en raíz, donde a los 18 días se observó un comportamiento similar en todos los tratamientos, siendo G. fasciculatum el único que alcanzó valores superiores al control con $14.37 \times 10^{-2}$ UAE. mg $\operatorname{prot}^{-1}$. A los 32 días se destacó este mismo tratamiento con $19.12 \times 10^{-2}$ UAE. mg prot ${ }^{-1}$, mientras que el resto presentó valores similares o inferiores al control.

Autores como Volpin et al. (1994) encontraron incrementos en la actividad de esta enzima en raíces de alfalfa inoculadas con $G$. intrarradices, a los 17 días, el que a las 24 horas posteriores decreció a valores inferiores a los del control. Además, estos autores observaron que dicha inducción ocurrió después que la manifestada por las enzimas quitinasas y CHI, por lo que asociaron su actividad a la penetración del hongo en la raíz y no a las señales previas. Blee \& Anderson (1996) al estudiar la acumulación de transcritos de ARNm de esta enzima en raíces de frijol inoculadas con $G$. intrarradices, no detectaron diferencias apreciables y observaron su 
acumulación sólo en las células que contenían arbúsculos. Resultados similares fueron encontrados por Harrison \& Dixon (1994) en raíces de alfalfa colonizadas por Glomus versiforme.

\section{Fenilalanina amonio liasa}

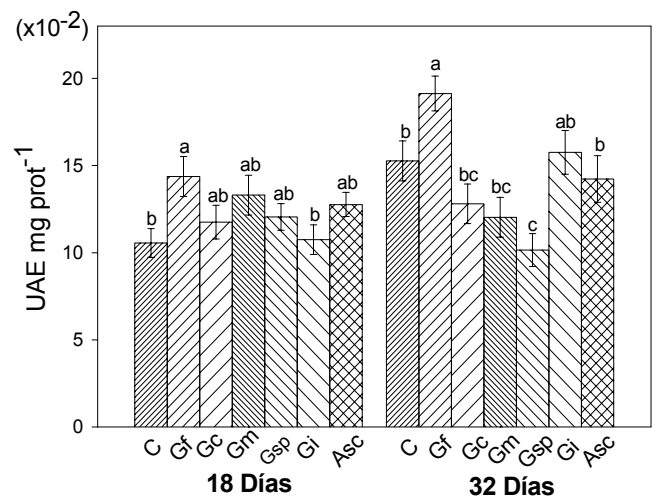

Figura 5. Actividad específica radical de las plántulas de tomate, var. "Amalia", inoculadas con seis cepas de hongos micorrízicos arbusculares, a los 18 y 32 días de germinadas.

Barras con letras comunes en cada grupo no difieren significativamente según el test de Duncan $(\mathrm{P} \leq 0.05)$. Leyenda: C- control, Gf- Glomus fasciculatum, Gc- $G$. clarum, Gm- G. mosseae, Gsp- Glomus sp.1, Gi- G. intrarradices, Asc- Acaulospora scrobiculata.

En general, los niveles de expresión de transcritos y/o actividad enzimática de la vía de los fenilpropanoides, en la simbiosis MA, difieren en el tiempo y en dependencia de las combinaciones planta - HMA (Dumas-Gaudot et al., 2000). Las evidencias expuestas se confirma con los resultados de este estudio, donde sólo se observó aumento de la actividad PAL en el tratamiento con $G$. fasciculatum, lo cual reafirma el comportamiento destacado de esta especie en las evaluaciones agronómicas, en los indicadores fúngicos $\mathrm{y}$ en el resto de los sistemas enzimáticos analizados.

Otros trabajos también apuntan hacia esta especie como la más efectiva para esta interacción en las condiciones estudiadas (Hernández, 2001; Llonín \& Medina, 2002; Solórzano et al., 2001).

\section{Conclusiones}

Los resultados demuestran que existen diferencias en el proceso de colonización de las distintas cepas de HMA, los cuales se evidencian en el comportamiento fúngico, agronómico y bioquímico de los tratamientos analizados, donde se destaca la cepa $G$. fasciculatum como la más efectiva para la interacción con el tomate, variedad "Amalia", en las condiciones estudiadas, en la etapa que abarcó este estudio.

Además, las diferencias en las actividades enzimáticas radicales detectadas indican la existencia de múltiples mecanismos de intercambio de señales entre la planta y el hongo, las cuales son específicas de la interacción simbiótica y presentan particularidades en dependencia de la cepa de HMA involucrada.

\section{Literatura citada}

Álvarez M., Armas de G. \& Martínez B. 1997. Amalia y Mariela, dos nuevas variedades de tomate para consumo fresco. Cultivos Tropicales. 18 (1): 83.

Blee K.A. \& Anderson A.J. 2000. Defense responses in plants to arbuscular mycorrhizal fungi. En: Current Advances in Mycorrhizae Research. Section II: Mycorrhizal fungi and plant defense. (G.K. Podila \& D.D. Douds Jr. eds.). APS Press, USA. : 27-44.

Blee K.A. \& Anderson A.J. 1996. Defense-related transcript accumulation in Phaseolus vulgaris $\mathrm{L}$. colonized by the arbuscular mycorrhizal fungus Glomus intraradices. Schenk and Smith. Plant Physiol. 110: 675-688.

Boller T. 1995. Chemoperception of microbial signals in plant cells. Ann. Rev. Plant Physiol. Plant Mol. Biol. 46: 189-214.

Boller T., Geheri A., Mauch F. \& Vogeli U. 1983. Chitinase in bean leaves: induction by ethylene, purification, properties and possible function. Planta. 157: 22-31.

Bonfante-Fasolo P. 1988. The role of the cell wall as a signal in mycorrhizal associations. En: Cell to cell signals in plant, animal and microbial symbiosis. (S. Scannerini let al./ eds.). Springer-Verlag. Berlin. Heidelberg. : 219-235.

Bradford M.M. 1976. A rapid and sensitive method for the quantification of microgram quantities of protein utilizing the principle of protein dye binding. Anal. Biochem. 73: 248-250.

David R., Itzhaki H., Ginzberg I., Galili G. \& Kapulnik Y. 1998. Suppression of tobacco basic chitinasse gene expression in response to colonization by the arbuscular mycorrhizal fungus Glomus intraradices. Mol. Plant Microbe Interact. 11 (6): 489-497.

Douds D.D.Jr., Galvez L., Bécard G. \& Kapulnik Y. 1998. Regulation of arbuscular mycorrhizal development by plant host and fungus species in alfalfa. New Phytol. 138: 27-35.

Dumas-Gaudot E., Gollotte A., Cordier C., Gianinazzi S. \& Gianinazzi-Pearson V. 2000. Modulation of host defence systems. En. Arbuscular Mycorrhizas: Physiology and Function. (Y. Kapulnik \& D.D. Douds Jr. eds.). Kluwer Academic Publishers. : 173-200.

Dumas-Gaudot E., Grenler J., Furlan V. \& Asselin A. 1992. Chitinase, chitosanase and $\beta-1,3$ glucanase activities in Allium and Pisum roots colonized by Glomus species. Plant Sci. 84: 17-24.

Espinosa-Victoria D. 2000. Diálogo molecular: hongo micorrízico arbuscular-raíz. En: Ecología, 
Fisiología y Biotecnología de la Micorriza Arbuscular. Alarcón, A. \& Ferrera-Cerrato, R. (eds.). IRENAT-Colegio de Postgraduados. Montecillo. Mundi Prensa. México. : 93-116.

Fernández F., Ortiz O., Martínez A., Costales A. \& Llonín D. 1997. The effect of commercial arbuscular mycorrhizal fungi (AMF) inoculants on rice (Oryza sativa) in different types of soils. Cultivos Tropicales. 18 (1): 5-9.

Fernández F., Rodríguez E.L. \& Gómez R. 1999. Caracterización de la efectividad de un nuevo inoculante micorrizógeno en Poaceas. Cultivos Tropicales. 20 (2): 9-14.

García-Garrido J.M., Cabello M.N., García-Romera I. \& Ocampo J.A. 1992. Endoglucanase activity in lettuce plants colonized with the vesiculararbuscular mycorrhizal fungus Glomus fasciculatum. Soil Biol. Biochem. 24 (10): 955959.

Gerdemann J.W. \& Nicholson T. H. 1963. Spore of mycorrhizae endogone species extracted from soil by wet sieving and decanting. Trans Br. Mycol. Soc. 46: 235-244.

Gianinazzi-Pearson V., Lemoine M.C., Arnould C., Gollotte A. \& Morton J.B. 1994. Localization of $\beta$ (1-3) glucans in spore and hyphal walls of fungi in the Glomales. Mycologia. 86: 478-485.

Giovanetti M. \& Mosse B. 1980. An evaluation of techniques to measure vesicular-arbuscular infection in roots. New Phytologist. 84: 489-500.

Gollotte A., Cordier C., Lemoine M.C. \& GianinazziPearson V. 1997. Role of fungal wall components in interactions between endomycorrhizal symbionts. En: Eukaryotism and Symbiosis (H.E.A. Shenck, R. Herrmann, K.W. Jeon \& N.E.M. Schwemmler, eds.). Springer, Berlin. : 412-428.

Graham L.S. \& Sticklen M.B. 1994. Plant chitinase. Can. J. Bot. 72: 1057-1083.

Harrison M.J. \& Dixon R.A. 1994. Spatial pattern of expression of flavonoid/Isoflavonoid pathway genes during the interaction between roots of Medicago truncatula and the mycorrhizal fungus Glomus versiforme. Plant. J. 6: 9-20.

Hernández A., Pérez J.M., Bosh D. \& Rivero L. 1999. Nueva Versión de Clasificación Genética de los Suelos de Cuba. Instituto de suelos. Edit. AGRINFOR. La Habana.

Hernández M.A. 2001. Dinámica de inducción de cinco sistemas enzimáticos, relaciones con los mecanismos de defensa en planta, en la simbiosis tomate-hongos formadores de micorrizas arbusculares. Tesis de grado. Facultad de Biología, Universidad de la Habana. INCA.

Herrera R.A., Ferrer R.L., Furrazola E. \& Orozco M.O. 1995. Estrategia de funcionamiento de las micorrizas VA en un bosque tropical. Biodiversidad en Iberoamérica. Ecosistemas,
Evolución y Procesos sociales. (Eds. Maximina Monasterio) programa Iberoamericano de Ciencia y Tecnología para el desarrollo. Subprograma XII, Diversidad Biológica, Mérida.

Koslova N.V., Strunnikova O.K., Labutova N.M. \& Muromtsev G.S. 2001. Production and specificity of polyclonal antibodies against soluble proteins from the arbuscular mycorrhizal fungus. Mycorrhiza.10: 301-305.

Lambais M.R. 2000. Regulation of plant defenserelated genes in arbuscular mycorhizae. En: Current Advances in Mycorrhizae Research. Section II: Mycorrhizal fungi and plant defense. (G.K. Podilla \& D.D. Douds Jr. eds.). APS Press USA. : 45-60.

Lambais M.R. \& Mehdy M.C. 1993. Suppression of endochitinase, $\quad \beta$-1,3-glucanase, chalcona isomerasa expression in bean vesicular-arbuscular mycorrhizal roots under different soil phosphate conditions. Mol. Plant-Microbe. Interact. 6: 75-83.

Lister C.E., Lancaster J.E. \& Walker J.R.L. 1996. Phenylalanine Ammonia-lyase (PAL) activities and its relationship to Anthocyanin and Flavonoids Levels in New Zealand- grown Apple Cultivars. J. Amer. Soc. Hort. Sci. (121): 281-285.

Llonín D. \& Medina N. 2000. Nutrición mineral con $\mathrm{N}, \mathrm{P}$ y K en la simbiosis hongos micorrizógenostomate (Lycopersicon esculentum Mill) en Ferralsol. Cultivos Tropicales. 23 (4): 83-88.

Morton J.B. \& Redecker D. 2001. Two new families of Glomales, Archaeosporaceae and Paraglomaceae, with two new genera Archaeospora and Paraglomaceae, based on concordant molecular and morphological characters. Mycologia. 93 (1): 181-195.

Noval B.M. 2000. Influencia de la sistemina sobre la actividad $\beta$-1,3-glucanasa y quitinasa en plántulas de tomate (Lycopersicon esculentum Mill) micorrizadas. Tesis para optar por el grado de Maestro en Ciencias, especialidad Biotecnología de las Plantas. Centro de Investigaciones y de Estudios Avanzados (CINVESTAV-IPN), Unidad de Irapuato. México.

Ortiz O. \& Fernández F. 1998. Efectividad del recubrimiento de semilla de arroz pregerminado con inoculante micorrizógeno arbuscular (ECOMIC). Cultivos Tropicales. 19 (2): 15-18.

Paynet M., Martin C. \& Girand M. 1971. Activité phenylalanine ammniae lyase et hypersensibilite an virus de la mosaique du tabac. Acad. Sci. Paris. 273: 537-539.

Phillips J.M. \& Hayman D.E. 1970. Improved procedures for clearing roots and staining parasitic and vesicular-arbuscular mycorrhizal fungi for rapid assessment of infection. Trans. Br Mycol. Soc. 55: 158-161.

Pozo M.J. 1999. Inducción de enzimas hidrolíticas en raíces de tomate (Lycopersicon esculentum) como 
respuesta a la formación de MA y su implicación en el control biológico de Phythophtora parasítica. Tesis de doctorado. Facultad de Ciencias, Universidad de Granada, España.

Rodríguez Y., Pérez E., Solórzano E., Meneses A. \& Fernández F. 2001. Peroxidase and polyphenoloxidase activities in tomato roots inoculated with Glomus clarum or Glomus fasciculatum. Cultivos Tropicales. 22 (1): 11-16.

Salzer P. \& Boller T. 2000. Elicitor induced reactions in mycorrhizae and their supresión. En. Arbuscular Mycorrhizas: Physiology and Function. (Y. Kapulnik \& D.D. Douds Jr. eds.). Kluwer Academic Publishers. : 1-10.

Simon L., Bousquet J., Lévesque R.C. \& Lalonde M. 1993. Origin and diversification of endomycorrhizal fungi and coincidence with vascular land plants. Nature. 363: 67-68.

Solórzano E. 1997. Inducción y caracterización parcial de proteínas asociadas con la patogénesis en la interacción tomate-Alternaria solani. Tesis para optar por el grado de Maestro en Ciencias en Bioquímica de las Proteínas. Facultad de Biología, Universidad de la Habana. CENSA. Dpto. Fisiopatología.

Solórzano E., Meneses A., Rodríguez Y., Pérez E., Fernández A., Peteira B. \& León O. 2001. Inducción de cinco sistemas enzimáticos en la simbiosis tomate-micorriza arbuscular. Revista de Protección Vegetal. 16 (1): 30-39,

Somogyi M. 1952. Notes on sugar determinations. J. Biol. Chem. 195: 19-23.

Terry E., Pino M.A. \& Medina N. 1998. Efectividad agronómica de Azofert y Ecomic en el cultivo del tomate (Lycopersicon esculentum Mill). Cultivos Tropicales. 19 (3): 33-37.

Trouvelot A., Kough J. \& Gianinazzi-Pearson V. 1986. Mesure du Taux de Mycorhization VA d'un Systeme Radiculaire. Recherche de Methodes d'Estimation ayantune Signification Fonctionnelle. Proceedings of the 1st European Symposium on Mycorrhizae: Physiological and Genetical Aspects of Mycorrhizae, Dijón, 1-5 July, 1985. (V. Gianinazzi-Pearson \& S. Gianinazzi, eds.). INRA, Paris. : 217-222.

Vázquez-Garcidueñas S., Leal-Morales C. \& HerreraEstrella A. 1998. Analysis of $\beta$-1,3-glucanolytic system of biocontrol agent Trichoderma harzianum. Appl. Environ. Microbiol. 64 (4): 1442-1446.

Volpin H., Elkind Y., Okon Y. \& Kapulnik Y. 1994. A vesicular-arbuscular mycorrhizal fungus (Glomus intraradix) induces a defense response in alfalfa roots. Plant Physiol. 104: 683-689.

\footnotetext{
${ }^{1}$ M. Sc. Laboratorio de Micorrizas. Departamento de Biofertilizantes y Nutrición de las Plantas. Instituto Nacional de Ciencias Agrícolas, carretera de Tapaste km 3 1⁄2 Gaveta Postal 1, cp. 32700, San José de Lajas, La Habana, Cuba, Correo electrónico yakelin@inca.edu.cu

${ }^{2}$ M. Sc. Laboratorio de Micorrizas. Departamento de Biofertilizantes y Nutrición de las Plantas. Instituto Nacional de Ciencias Agrícolas, carretera de Tapaste km 3 1⁄2 Gaveta Postal 1, cp. 32700, San José de Lajas, La Habana, Cuba.

${ }^{3}$ Dr. C. Laboratorio de Micorrizas. Departamento de Biofertilizantes y Nutrición de las Plantas. Instituto Nacional de Ciencias Agrícolas, carretera de Tapaste km 3 1⁄2 Gaveta Postal 1, cp. 32700, San José de Lajas, La Habana, Cuba.

${ }^{4}$ Dr. C. Laboratorio de Micorrizas. Departamento de Biofertilizantes y Nutrición de las Plantas. Instituto Nacional de Ciencias Agrícolas, carretera de Tapaste km 3 1⁄2 Gaveta Postal 1, cp. 32700, San José de Lajas, La Habana, Cuba.
} 